\title{
FORMATIVE ASSESSMENT OF GLOBAL EDUCATION -JAPANESE HIGH SCHOOL STUDENTS' CONCEPTIONS OF A GLOBAL LEADER-
}

\author{
Hiromi Ishimori ${ }^{1}$ \& Masahiro Arimoto ${ }^{2}$ \\ ${ }^{I}$ Miyagi-pref. Sendai Nika High School / Teacher (Japan) \\ ${ }^{2}$ Tohoku University / Professor (Japan)
}

\begin{abstract}
The purpose of this poster presentation is to investigate the characteristics of Japanese high school students' conceptions of a "global leader". In an increasingly globalized world, it is critical to strengthen the development of capabilities for cultivating human resources for global operation activities. For this purpose, in 2014, a new global education project called Super Global High School (SGH) was initiated by the Japan's Ministry of Education, aiming at cultivating global leaders at the secondary education level. In order to allow students to perform globally in the future, students are to learn high levels of education, communication skills and imagination as well as about concerns such as various social problems. These certified schools are expected to design a curriculum with a profile of their ideal leader in addition to setting specific research topics during the designated period (five years, concluding in March 2019). In order to investigate students' conceptions and awareness caused by SGH learning experiences, a focus group discussion (FGD), one of the qualitative techniques for data collection, was conducted. FGD also functioned as formative assessment, since the students were able to obtain reflection and feedback on their own learning, promoting meta-cognition skills. In the poster, I will make a presentation on the students' images of a global leaders.
\end{abstract}

Keywords: Japanese high school students, super global high school (SGH), global leaders, global education, formative assessment.

\section{Objectives}

The purpose of this study is to investigate the characteristics of Japanese high school students' conceptions of a "global leader". I will explore what a global leader should be like, with an analysis of the images of ideal global leaders that Japanese high school students think after experiencing various global learning activities. Also, I will discuss how formative assessment strategies will work in their learning.

In order to allow students to perform globally in the future, students are to learn high levels of education, communication skills and imagination as well as about concerns such as various social problems. These certified schools are expected to design a curriculum with a profile of their ideal leader in addition to setting specific research topics during the designated period (five years, concluding in March 2019).

According to MEXT, there are six main efforts to be made by SGHs; 1) Definition of Ideal Global Leader Profiles, 2) Research and Development Themes, 3) Global Business and Social Issues, 4) Theme-based Research, 5) Collaboration with Universities, 6) Collaboration with International Organization and Companies. This study focused on 4) Theme-based Research (Exploratory Studies and Overseas Fieldwork), specifically, "Overseas Fieldwork", which is set as a core activity in our SGH program.

Practices at Miyagi-Pref. Sendai Nika High school, which is designated as an SGH and is putting a lot of resources into global education, will be analyzed as an example case in this research. By investigating students' awareness developed by SGH learning experiences and finding out the characteristics of their conceptions of a "global leader", some implications will be provided for designing a better global education program. 


\section{Research}

\subsection{Introduction of the SGH curriculum}

Sendai Nika's SGH's research theme is: An Inquiry into Global Water Problems in the Field of the Kitakami and Mekong Rivers. Water problems are one of the critical global issues taken up by UNESCO. In addition, they are one of the key targets in the Sustainable Development Goals (SDGs), which have recently had more focus placed on them by Japanese education.

The curriculum is designed with a core set of approaches to solve water problems in the world. They learn about water problems locally, and then they are able to expand their interest to broader areas of Asia through research tasks. In order to learn about domestic and international water problems, there are plenty of active, participatory and experiential learning opportunities for students, such as Local Fieldwork, Overseas Field Trip/Cultural Understanding, International Exchange Program, Overseas Fieldwork/Community Involvement, and International Academic Conference. Among them, "the Mekong fieldwork" is the most stimulating activity in the SGH program of this school. Students learn about water issues in the Mekong Basin, conducting research and community involvement activities which they have planned in advance. Sendai Nika H.S. set ideal global leader qualities and abilities as the expected outcomes of the SGH program.

\subsection{Method}

In order to explore students' conceptions and awareness gained by SGH learning experiences, a focus group discussion (FGD), one of the qualitative techniques for data collection, was conducted. It was analyzed with particular attention towards formative assessment.

Formative assessment is the frequent assessment of students' understanding and progress in order to identify learning needs and difficulties, give feedback, and tailor teaching strategies (CERI, 2005). OECD revealed that it is one of the most effective strategies for promoting high performance in schools. In fact, OECD reports that several countries promote formative assessment as a fundamental approach to education reform. Also in Japan, the idea of formative assessment has been incorporated into the new Courses of Study.

Table 1. Profile of Focus Groups (FGs)

\begin{tabular}{|c|c|}
\hline $\begin{array}{l}\text { Discussion theme: What is a Global Leader Like? } \\
\text { FGD Activity procedure: 1) List abilities/capabilities/s } \\
\text { 2) Give and exchange opini } \\
\text { 3) Categorize the abilities o } \\
\text { 4) Think about the reason at } \\
\text { 5) Categorize subheading 6 }\end{array}$ & $\begin{array}{l}\text { lls of "global leader", individually } \\
\text { ss over discussion } \\
\text { sills they think are important } \\
\text { share ideas or experiences } \\
\text { ntensify discussion }\end{array}$ \\
\hline FG1 & FG2 \\
\hline Date: September 10 $0^{\text {th }}$, Monday, 2018 (Time: 12:20 13:00) & Date: December $4^{\text {th }}$, Thursday, 2018 (Time: $14: 45 \sim 16: 15$ ) \\
\hline $\begin{array}{l}\text { Participants: All of the } 2^{\text {nd }} \text { grade High School students } \\
\text { who took part in the Mekong filed work held in } \\
\text { Summer } 2018 \text { (there are } 8 \text { in total) }\end{array}$ & $\begin{array}{l}\text { Participants: All of the } 3^{\text {rd }} \text { grade High School students } \\
\text { who take Project Study and experienced presentaions at } \\
\text { academic conferences (there are } 14 \text { in total) }\end{array}$ \\
\hline
\end{tabular}

As shown in Table 1, there are two FGs being questioned. As for FG2, as a part of formative assessment strategies, student's feedback on the self-assessment worksheet was analyzed as evidence.

\section{Discussion}

The most frequently appearing key word in the discussion among FG1 is "the other person's situation". This exactly signifies the ability that our school expected the students to acquire through the SGH program. In other words, "the other person's situation" is the right point to connect with "The power of empathy", which is one of the five qualities and abilities that we want students to learn as global leaders. They think that to sympathize with another person's position or feeling is the most important trait of a global leader. Awareness of this view point developed in daily classes and was enforced through the fieldwork; this is because the two teachers in charge of this fieldwork and the SGH Project Study did not directly mention the five expected traits to the students.

Of course, there are more profiles of "global leader", but they are categorized into several groups subtitled by the students as; "Respect" "Cross-cultural understanding" "Viewpoints" "Actions" "Consideration for others, Cooperation/Harmony", and "Leadership/leader-spirit". They used their experiences from fieldwork to formulate ideal global leaders, by conceptualizing their global awareness.

We have confirmation that the overseas fieldwork contributed to developing qualities and abilities which we want students to learn as global leaders. On the other hand, it is unclear whether or not 
the students obtained the other four abilities. Based on FGD, however, the same holds for the overseas fieldwork more or less contributing to developing these skills.

A similar tendency can be seen in FGD2, but it is noticeable that the discussion was much deeper and the students listed a lot more key words describing ideal global leaders. This is because they are one year senior with more learning experiences including making presentations at domestic or international academic conferences. An example of this is that in addition to various profiles which appeared in the discussion conducted by FG1, FGD2 assembled more skills and abilities as global leaders into the "Facilitation" and "Discussion skills" categories.

According to self-assessment sheets submitted by FG2, learning that occurred from joining academic conferences falls mainly into these four categories; 1) learning regarding communication and presentation techniques (effective presentation, explanation skills and ways to convey something in a way that's easy to understand) ; 2) learning regarding viewpoints (understanding the importance of having multiple viewpoints, viewing a matter objectively, considering things from different angles and to verifying the effects from new perspectives) ; 3) learning regarding thinking skills (to think deeply and logically); 4) learning regarding research \& study (motivation to research at university, some mindsets as a researcher). Apart from those, stimulation, broadened horizons, self-esteem, flexible approach etc. were introduced.

With regard to teaching and learning methodology, I found that FGD functioned as their formative assessment and aroused their reflection. Though the discussion, they were able to understand what they had learned by reflecting on their learning. Also, they were able to think or rethink about things from different viewpoints, which expanded their views. To promote learning, it is indispensable that a learner identifies what he or she has done well and focuses on what he or she can do to improve (Black \& Wiliam, 1998). Students should be engaged in a reflective and critical review of the work they have done to enable them to plan their revision effectively. Formative assessment including reflection and feedback by group discussion and self-assessment sheet is an effective way to deepen their understanding.

Several weeks after the academic conference, one student in FG2 wrote on the self-assessment sheet: "Looking back to those days when I was devoted to doing my best for my research presentation, I feel grateful for this opportunity that I need to reflect my learning. Now I realize that as days passing by, my passion which was burning at that time is being disappearing day by day. From now on, I will try not to forget my next goal." This can identify the cardinal importance of formative assessment, showing proof of how self-assessment as reflection is important to having a learner acknowledge their hidden desires for self-realization. In this sense, formative assessment is a significant tool to promote meta-cognition skills and to boost student learning, empowering learners.

\section{Conclusions}

Through the discussion above, it is clear that SGH's programs had a great impact on the students, and helped them raise their consciousness of global awareness and international-mindfulness. Overseas fieldwork especially enhanced knowledge and awareness obtained in classes (Project Study) at school and even made a momentous contribution to increasing global citizenship which is thought to be necessary to establish a more peaceful and sustainable world. Their conceptions of a "global leader" have been formulated by a mixture of their rich experiences.

Furthermore, they were able to understand what they had learned by reflecting on their learning and finding what they can do at present and what they need for the next step. It is essential to provide learners with opportunities to have self-assessment feedback in the learning process, and engagement in feedback and reflection works as a significant formative assessment to develop their skills as well. By implementing both self and group assessment, their chances of deepening learning will be increased.

Owing to the abundant activities and experiential learning of the SGH program, their global awareness has surely been fostered and it seems they have appropriate, relevant and profound conceptions of global leaders. However, it is uncertain whether they will really become true global leaders and it is still unknown that what kind of role they will actually play in the future. It is important to keep watching over their development long term.

\section{References}

Ishimori, H. (2013. Design and Assessment of Global Education at a School-based Class. [Global Kyoiku no Jyugyo Sekkei to Assessment] Tokyo: Gakujishuppan.

MEXT (2018). The minutes of the second meeting of the panel of experts on SGH program's verification. http://www.mext.go.jp/a_menu/kokusai/sgh/1404423.htm (accessed December 16, 2018) 